\title{
Outubro de 68 \\ e o sentido do radicalismo
}

Franklin Leopoldo e Silva

Professor do Departamento de Filosofia

FFLCH-USP

\begin{abstract}
"A Faculdade de Filosofia, a partir de sua fundação, em 1934, foi um fermento de radicalizaçāo intelectual no quadro do ensino superior de São Paulo. Um quarto de século depois, a rua Maria Antonia, sempre dentro dos limites da classe média, foi o sinal de uma radicalização mais ampla, que lançava pontes para o mundo da ação política e do operariado. Ela promoveu uma substituição de radicalismos dentro do novo espírito que vem quebrando os conceitos e as normas tradicionais [...]" (Antonio Candido, "O Mundo coberto de Moços", in Maria Antonia: uma rua na contramão, São Paulo, Nobel, 1988).
\end{abstract}

Este texto pode ser tomado como motivo para dizer alguma coisa sobre um tema importante, difícil, complexo, repleto de ambigüidades, mas sem o qual talvez nada se pudesse compreender acerca da Maria Antonia e da Faculdade de Filosofia, Ciências e Letras, hoje a Faculdade de Filosofia, Letras e Ciências Humanas da USP. E este tema é o radicalismo.

Por que este tema é importante? Porque ele define a Faculdade de Filosofia, marca a sua origem histórica e caracteriza o que poderíamos chamar o espírito do projeto idealizador da Faculdade e, por extensão, da USP. Primeiramente, é preciso entender este radicalismo no contexto histórico da fundação da Universidade, para tentar recuperar o seu sentido, já que, visto à distância, ele pode parecer um misto, mesmo algo de disforme, uma composição mal-acabada de ideologia e utopia. Mas se atentarmos para o componente intelectual e cultural deste radicalismo, talvez possamos resgatar, no fundo da mistificação histórico-política, algumas convicções e algumas esperanças que de alguma maneira sobreviveram às próprias 
intenções, formuladas e não formuladas, do grupo fundador de USP, que por certo tinha um projeto de hegemonia e de poder, do qual a Universidade deveria ser o instrumento. Ocorre que as circunstâncias históricas e as tensões políticas da época levaram à construção de um instrumento que, para ser eficaz, tinha de ser crítico, tinha de ser, precisamente, radical, para adequar-se à realização do movimento histórico que dele se esperava. Nisto o projeto de fundação da USP se diferenciava do modo como foram implantadas as outras universidades brasileiras. E esta radicalização necessária, que deveria traduzir-se num movimento controlado de mudança a partir de um projeto político-educacional de perfil ideológico definido, acabou tomando uma feição própria desde que passou a fazer parte de uma ordem de acontecimentos históricos que os fundadores não podiam, evidentemente, controlar. Mas a determinação profunda e originária se manteve durante muito tempo, o que nos coloca hoje a questão de como compreender o seu desaparecimento.

Por que o tema é difícil? Porque este radicalismo como determinação originária de um projeto político-educacional foi gestado no interior de um projeto histórico-político mais amplo de caráter liberal. As tensões políticas da época, a que me referi há pouco, opunham os liberais de então, e especialmente o grupo paulista, às oligarquias que monopolizavam o poder. No interior deste quadro, os liberais podiam fazer de si próprios uma imagem ligada à transformação da sociedade, que deveria ser operada por meio de uma renovação profunda da formação do político, entendida como via para a renovação da política. Daí o caráter central do projeto educacional, profunda e inteiramente atravessado pelo eixo da vontade política do poder, que deveria ser o resultado da transformação. A radicalização crítica entendida como produção e disseminação do conhecimento no âmbito do ensino superior era então idealizada como antídoto ao autoritarismo inculto das oligarquias e dos seus prepostos governamentais. Mas o liberalismo tem uma vulnerabilidade congênita: ele facilmente se deixa contaminar pelo autoritarismo com o qual convive mesmo que esta convivência seja conflituosa. De modo que o liberalismo está como que fatalmente destinado a se tornar autoritário quando ocupa o lugar do autoritarismo. Por isto a vitória do liberal sobre o autoritário é sempre uma meia vitória e a derrota do autoritário, meia derrota. Isto explica 


\section{Outubro de 68 e o sentido do radicalismo}

porque, na Universidade do projeto liberal, pouco depois da celebração do espírito livre que presidira à sua fundação, esta liberdade teve de ser disciplinada para amoldar-se à nova configuração de um poder que os antigos adversários passaram a dividir, até por concessão dos primeiros ocupantes.

A terceira característica a que nos referimos antes, a complexidade do tema, aparece então nestes termos: o radicalismo da Faculdade de Filosofia deve agora afirmar-se contra o próprio projeto que o concebeu, tendo que voltar-se, para sobreviver, contra as intenções de hegemonia de classe que no projeto se traduzia como formação das elites dirigentes. Esta talvez tenha sido a primeira ocasião em que a Universidade, especialmente a Faculdade de Filosofia, Ciências e Letras, descobriu-se conscientemente como à margem do seu tempo histórico. E esta necessidade de recompor a sua radicalidade assumindo a sua marginalidade foi o primeiro passo para tentar transpor a distância entre a falsa autonomia e a autonomia real que, diga-se desde já, ela nunca chegou a conquistar como atributo duradouro. A complexidade deriva portanto da necessidade de inserir-se no movimento da história por via da recusa parcial do seu tempo histórico. $O$ que isto acarreta em termos de risco de isolamento só poderia ser compensado por uma reflexão extremamente cuidadosa que viesse a definir e avaliar as mediações presentes na inserção social e histórica da universidade. Esta reflexão, creio eu, nunca foi feita de modo inteiramente equilibrado. De forma que o radicalismo passou, num certo período, por uma oscilação entre o isolamento e a imersão total no plano das necessidades sociais.

Esta oscilação configura, no meu entender, a ambigüidade, última das características que assinalamos acima como estando presentes no tema do radicalismo da Universidade e especialmente da Faculdade de Filosofia. Nascida para orientar e dirigir, a Universidade viu-se logo como dirigida e orientada por forças históricas que atuavam no plano mais amplo da sociedade e que repercutiam na instituição universitária de modo semelhante ao que ocorria em todas as outras instituições. Vendo-se desta maneira forçosamente arrastada no movimento histórico, a Universidade deveria talvez ter retornado reflexivamente às suas origens, à duplicidade inerente aos propósitos político-educacionais do projeto original, e então ter-se dedicado a repensar profundamente o significado da formação. Mas não houve tempo para isto. O máximo que a Universidade conseguiu fazer 
foi embarcar atabalhoadamente nas "reformas" que pretendiam redefinir o seu perfil, estratégia que lhe foi imposta como condição de sobrevivência. E então o radicalismo se manifestou muito mais pela sua contrapartida, pelo caráter reativo inerente à atitude de reformar precipitadamente para integrar-se numa modernidade que ela nem tivera tempo de pensar e já lhe ia sendo impingida goela abaixo. A ambigüidade entre gerir uma transformação e sofrer uma transformação instalou-se então revelando à plena luz uma indecisão talvez bem mais anterior e mesmo originária. Por isto a reforma da USP coincidiu em tantos pontos muito mais com as pressões externas do que com uma reinvenção consciente do projeto de universidade. Isto demonstra que a Universidade, ainda jovem, já dava a esta altura mostras de uma impressionante vulnerabilidade para introjetar mecanismos de autodissolução e de alienação de sua autonomia. A extinção da Faculdade de Filosofia, Ciências e Letras, quaisquer que sejam as razões técnicas que a motivaram, é testemunho eloqüente do desencadeamento de um processo a que continuamos assistindo.

É interessante notar que, em meio às reformas, discutidas, consentidas, partilhadas e por vezes recusadas, o radicalismo da Universidade, especialmente o da Faculdade de Filosofia, Ciências e Letras, encontrou uma forma de manifestar-se que certamente foi a mais profunda, intensa e fulgurante dentre todas as que ocorreram. O que ocorreu na Maria Antonia, na década de 60 e especialmente no período de dois ou três anos que antecederam o outubro de 1968, de alguma maneira pode ser explicado parcialmente pela história da Universidade, se a virmos marcada pelo radicalismo de que vimos falando, mas de maneira alguma pode ser entendido como simples continuidade. Diz o texto de Antonio Candido que citamos no início que a Maria Antonia "promoveu uma substituição de radicalismos dentro do novo espírito que vem quebrando os conceitos e normas tradicionais (...)" Se refletirmos sobre esta expressão "substituição de radicalismos", talvez pudéssemos retomar algo do que se disse há pouco acerca da necessidade de uma reflexão profunda da Universidade sobre si mesma, não do ponto de vista de modificações pontuais no seu funcionamento e na sua organização, mas no seu próprio modo de ser, na assimilação de sua história, na posse efetiva de seu passado e na projeção de suas possibilidades futuras. Isto que a Universidade não foi capaz de 


\section{Outubro de 68 e o sentido do radicalismo}

fazer, ou talvez não tenha podido fazer, a urgência daquele presente a levou a efetuar, não na forma de um pensamento tranqüilo, ponderado e articulado, mas numa conjunção dramática entre o pensamento e a ação, própria dos momentos de ruptura, numa circunstância em que as pessoas foram forçadas a compreender que de nada valem as idéias e as palavras se elas não se transformam em atos. Arrastada pelo movimento histórico, colhida, assim como o país, no torvelinho da barbárie, do obscurantismo, da violência, talvez a universidade tenha rememorado a sua história com a nitidez instantânea e alumbrada daquele que se vê na iminência da morte. O fato é que uma certa seqüência de ações, que naquele momento se deram, à margem das instâncias oficiais da Universidade e contra elas, fizeram com que, num certo momento, a Faculdade de Filosofia, Ciências e Letras tivesse o seu destino nas mãos. Isto dito a partir de hoje, e sobretudo a partir disto em que hoje a Faculdade se transformou, pode soar grandiloqüente, pretensioso e ingênuo, porque, como diz Antonio Candido em outra parte do texto, "a impressão poderia ser que nada deu certo" Com efeito, eu creio que uma definição pertinente do que aconteceu na Maria Antonia consistiria em dizer que se trata de um episódio inacabado, e creio também que daí vem a dificuldade de reconstituição. Esta é a razão pela qual não vou tentar fazer aqui uma análise mais detalhada dos acontecimentos.

Somente gostaria de insistir, na linha do que vem sendo dito, na questão do radicalismo e no significado que ele assumiu em 1968. Antonio Candido se refere a isto como "uma radicalização mais ampla, que lançava pontes para o mundo da ação política e do operariado" Também aqui creio que se pode dizer que a Universidade, repensando na ação as suas origens, ainda que de modo implícito, reconheceu-se não como a instância preparadora dos políticos que iriam renovar a política, como pretendiam os liberais fundadores, mas como lançada na ação política, menos por vontade própria do que pela opressão que a ameaçava. Não deixa de ser interessante notar que enquanto se discutiam as reformas, de um lado, crescia o radicalismo, de outro. Talvez isto se explique por uma certa mudança da imagem que a Faculdade de Filosofia tinha da Universidade, que teria ocorrido naquele momento e durou apenas enquanto duraram os acontecimentos. A imagem ampliada de uma Universidade que, a partir de sua peculiaridade institucional, poderia marcar novos rumos não apenas 
para a Escola, mas para a própria vida das pessoas. Já se disse que a Maria Antonia, mais do que uma Faculdade ou a rua em que esta se localizava, era um modo de vida. Creio que o radicalismo político era um modo de viver esta proposta radical de vida, na urgência de um tempo violento e incerto. E nisto a Maria Antonia refletia o Maio francês, em que as propostas não se orientavam pelo pragmatismo político, mas pela vontade de reinventar a vida e o mundo, propostas que por um momento pareceram realistas, tal a força da convicção com que eram sustentadas. Somente nos momentos autenticamente revolucionários a Política se engrandece com a força da esperança e da utopia, ainda que estes momentos sejam breves, durem o instante da ruptura e desapareçam para sempre naquilo que tiveram de mais importante, restando apenas aquilo que o futuro apequenou para guardar nos escaninhos de uma memória insuficiente, empobrecedora, falsificadora e por vezes aviltante. O radicalismo foi, sim, uma determinação originária do núcleo gerador da USP, a Faculdade de Filosofia. Mas ele só foi manifestado e vivido em toda a sua dimensão no tempo do desaparecimento, no tempo da violência da morte premeditada, da morte como processo que a Universidade passou a viver desde então, cujas etapas se vão acumulando a cada passo que a Universidade e a Faculdade dão no sentido de adentrar aquilo os gestores da sua morte entendem como progresso, modernização e racionalização.

Hoje o prédio da Maria Antonia é um Posto de Serviços de Extensão da Universidade, e por ironia simbólica, é chamado de Centro Universitário. O CET, que é um outro Centro, o de Engenharia de Tráfego, talvez tenha sido mais sensível. Manteve a Maria Antonia contramão para quem vem do lado do Mackenzie. 